\title{
A REFORMA DO ENSINO MÉDIO DO GOVERNO TEMER, A EDUCAÇÃO BÁSICA MÍNIMA E O CERCO AO FUTURO DOS JOVENS POBRES
}

\author{
R. M. L. ARAÚJO \\ Programa de Pós-Graduação em Currículo e Gestão da Escola Básica da Universidade Federal do Pará \\ rlima@ufpa.br \\ Submetido 07/03/2018 - Aceito 10/12/2018 \\ DOI: $10.15628 /$ holos.2018.7065
}

\section{RESUMO}

Tratamos da Reforma do Ensino Médio implementada pela Medida Provisória n. 746, de 2016, e depois consolidada na Lei n. 13.415/17. Fazendo uso de pesquisa documental e bibliográfica, problematizamos suas pretensas finalidades de melhoria da qualidade da educação por meio da flexibilização curricular e da ampliação das escolas com jornada de tempo integral. Defendemos que seu real objetivo é relativizar alguns conceitos importantes da educação nacional, tais como a
\end{abstract}

educação básica, a educação pública, estatal e gratuita e a profissionalização docente. Concluímos que a Reforma em curso, de um lado, responde a interesses de seus principais interlocutores, o CONSED e o Movimento Todos pela Educação, ao flexibilizar a necessidade de contratação de professores licenciados, direcionar o currículo para a formação das "personalidades produtivas" e ampliar o mercado de serviços educacionais. De outro lado, a Reforma limita o futuro dos jovens.

PALAVRAS-CHAVE: Ensino Médio, Política Educacional, Reforma do Ensino Médio, Juventude.

\section{THE HIGH SCHOOL REFORM FROM GOVERNMENT TEMER, THE MINIMUM BASIC EDUCATION AND THE SIEGE OF THE FUTURE OF YOUNG POOR PEOPLE}

\begin{abstract}
In this paper we discussed about the brazilian High School Reform implemented by Provisional Measure n. 746, of 2016, and then consolidated in the Law no. 13.415 / 17. By using documentary and bibliographical research, we problematize its supposed purposes of improving the quality of education through curricular flexibilization and the expansion of schools with a full-time working day. We defend that the real purpose of this reform is to relativize some important concepts of national
\end{abstract}

education, such as basic education, public, state and gratuitous education and teacher professionalization. We conclude that the ongoing Reform, on the one hand, responds to the interests of its main interlocutors, such as "All for Education" movement, by making flexible the need to hire licensed teachers, direct the curriculum to the formation of "productive personalities" and To expand the market for educational services. On the other hand, the Reform limits the future of young people.

KEYWORDS: High School, Educational Policy, High School Reform, Youth. 


\section{INTRODUÇÃO}

Foi editada, no dia 22 de setembro de 2016, a Medida Provisória n. 746, que introduziu uma reforma na legislação que regulamentava o Ensino Médio no Brasil. Após um curto período de tramitação (e quase nenhum debate), no dia 16 de fevereiro de 2017 esta MP foi aprovada, com algumas pequenas alterações, pelo Congresso Nacional, ganhando forma final na Lei $n$. 13.415, que dá materialidade a uma substantiva mudança no Ensino Médio Brasileiro com forte potencial de impacto (negativo) na vida dos jovens pobres desse país.

Para que possa ter o alcance desejado por seus idealizadores, esta Lei alterou, ao mesmo tempo, a LDB - Lei de Diretrizes e Bases da Educação Nacional (Lei n. 9.394, de 20 de dezembro de 1996), a Lei do FUNDEB - Fundo de Manutenção e Desenvolvimento da Educação Básica e de Valorização dos Profissionais da Educação (Lei n. 11.494, de 20 de junho de 2007), a Consolidação das Leis do Trabalho e instituiu uma "Política de Fomento à Implementação das Escolas de Ensino Médio em Tempo Integral".

Por sua abrangência e por seu alcance, essas alterações em um conjunto de leis configura uma profunda reforma na educação básica nacional, em particular no Ensino Médio, com repercussões sobre as finalidades da educação nacional, sobre a organização curricular dessa etapa de ensino, bem como sobre o trabalho pedagógico, o financiamento da educação básica, o trabalho docente e futuro profissional dos egressos dessa etapa de ensino. Essa Reforma foi justificada pelo Ministro da Educação, Mendonça Filho, como uma estratégia de enfrentamento ao ensino desinteressante e de má qualidade ofertado à juventude brasileira.

Problematizamos aqui as pretensas finalidades da Reforma de busca da melhoria da qualidade da educação por meio da flexibilização curricular e da ampliação das escolas com jornada de tempo integral e defendemos que sua real finalidade é flexibilizar alguns conceitos importantes da educação nacional, conquistas das lutas dos estudantes e dos trabalhadores em educação, tais como a educação básica, a educação pública e gratuita e a profissionalização docente.

Focamos no conteúdo dessa Reforma e argumentamos que é possível identificar alguns impactos sobre a educação básica, tais como o aprofundamento de processos de exclusão dos jovens em situação de maior vulnerabilidade, o aprofundamento das desigualdades sociais, a maior desqualificação da educação básica, principalmente para os mais pobres, e a desvalorização dos profissionais da educação.

Concluímos que a Reforma em curso responde a interesses de seus principais interlocutores, o CONSED - Conselho Nacional de Secretários de Educação, ao flexibilizar a necessidade de contratação de professores licenciados, e o Movimento Todos pela Educação, ao direcionar o currículo para a formação das "personalidades produtivas" e estimular o "mercado de serviços educacionais" ${ }^{1}$.

${ }^{1} \mathrm{O}$ artigo de Ferretti e Silva (2017) demonstra, por meio de análise dos argumentos oficiais, da argumentação dos participantes convidados para as audiências públicas e do conteúdo do HOLOS, Ano 34, Vol. 08 


\section{O CONTEXTO DA REFORMA}

Essa Reforma dá continuidade a uma série de medidas de igual teor que foram implementadas desde a década de 1990 no Brasil, que visavam subordinar a educação e, em particular, o ensino médio, as demandas imediatas dos setores produtivos conferindo-lhe um caráter mais instrumental. A Reforma traz, como uma de suas marcas, a forma antidemocrática como foi implementada, conduzida e aprovada. Inicialmente implementada como Medida Provisória, que tem força de lei desde a sua edição, alterou bruscamente duas das mais importantes regulamentações da educação nacional, a LDB e a Lei do FUNDEB, mesmo havendo um parecer contrário da Procuradoria Federal dos Direitos do Cidadão e do Ministério Público Federal alertando para os riscos de uma reforma do Ensino Médio Brasileiro por meio de Medida Provisória².

A sua discussão no Congresso Nacional também foi atropelada e apressada, tramitando em menos de 5 meses, levada de forma antidemocrática, porque sem uma séria discussão com a sociedade ou mesmo no Congresso Nacional. Sequer foram ouvidas as entidades historicamente representativas do campo científico e educacional que, na sua grande maioria, lançaram notas com as quais se manifestavam contra a Reforma proposta ${ }^{3}$.

Trata-se, portanto, de uma reforma construída sem debates com os principais protagonistas da educação básica, quais sejam: professores, alunos e pais de alunos, e que teve como interlocutores principais grandes grupos empresarias, como os que compõem o Movimento Todos Pela Educação ${ }^{4}$, e o CONSED, que tinha como uma de suas principais demandas a flexibilização do trabalho docente. Os interesses desses dois interlocutores, que têm

Projeto de Lei que resultou na Medida Provisória, que foram os participantes ligados ao setor privado os principais interlocutores atendidos na conversão da MP em Projeto de Lei n³4/2016.

${ }^{2}$ Ver Nota em: http://pfdc.pgr.mpf.mp.br/informativos/edicoes-2016/setembro/pfdc-lanca-nota-publicasobre-riscos-de-reforma-do-ensino-medio-por-meio-de-medida-provisoria/.

${ }^{3}$ Destacam-se as seguintes entidades, que emitiram notas em repúdio ao conteúdo da Medida Provisória: ANPED (Associação Nacional de Pós-Graduação e Pesquisa em Educação), SBPC (Sociedade Brasileira para o Progresso da Ciência), ANPAE (Associação Nacional de Política e Administração da Educação), UBES (União Brasileira dos Estudantes Secundaristas), CNTE (Confederação Nacional dos Trabalhadores em Educação), ANFOPE (Associação Nacional pela Formação dos Profissionais da Educação), Cenpec (Centro de Estudos e Pesquisas em Educação, Cultura e Ação Comunitária), FONEC (Fórum Nacional de Educação do Campo), ABRAPEC (Associação Brasileira de Pesquisa em Educação em Ciências), Fórum Nacional de Educação, Intercrítica (Intercâmbio Nacional dos Núcleos de Pesquisa em Trabalho e Educação), ABH (Associação Brasileira de Hispanistas), CBCE (Colégio Brasileiro de Ciências do Esporte) e Sociedade Brasileira de Sociologia.

4 “O 'Todos pela Educação' é hegemonizado por grandes grupos de empresários que disputam, no seio do Estado Brasileiro, os recursos do fundo público para seus empreendimentos e também a direção da concepção da educação. Institutos ligados a bancos, grupos da grande mídia, associações de grupos empresariais como a Associação Brasileira do AgroNegócio (ABAG) produzem cartilhas e coordenam participam das gestões municipais e estaduais da educação básica pública" (Frigotto, 2017). 
assumido na história recente brasileira um protagonismo de cunho conservador na área de educação, foram atendidos no conteúdo da Reforma.

A sua aprovação se deu em uma conjuntura nacional e internacional marcada pelo crescimento de forças conservadoras e se integra, no Brasil, a uma agenda do governo ilegítimo liderado por Michel Temer, imposto por meio de um golpe jurídico-midiático-parlamentar (Saviani, 2017), que visa promover, entre outras finalidades, a retirada de direitos sociais em benefício do grande capital. Entre essas medidas, destaca-se a Proposta de Emenda Parlamentar 55 (PEC 55), aprovada, que congela por 20 anos os gastos do governo com a área social, a privatização do pré-sal, a Reforma da Previdência e a Reforma Trabalhista, que ameaçam um conjunto de direitos dos trabalhadores dos setores público e privado, e a Lei das Terceirizações que, além de facilitar a adoção de formas precárias de trabalho, permite a contratação de empresas terceirizadas para a realização de atividades meio, como o ensino público.

A reforma do Ensino Médio compôs como mais uma peça de um mosaico que vai se montando no Brasil, tecendo uma imagem de país crescentemente desigual, plutocrático e excludente.

\section{QUAIS AS MUDANÇAS PROMOVIDAS PELA REFORMA?}

A nova legislação alterou a LDB, principal lei regulamentadora da educação nacional, e a Lei do FUNDEB, que define o financiamento da educação básica no país. Suas mudanças, portanto, atingem a toda a educação básica e não apenas o Ensino Médio, apesar de focar nesta etapa do ensino.

Apresenta-se como "Política Nacional de Educação em Tempo Integral", mas, em relação a isso, apenas expõe as diretrizes de um "programa", algumas das quais precisam ser complementadas e/ou regulamentadas. Essa Lei e sua pretensa política de educação de tempo integral, tal como na história grega do cavalo de Tróia, apresenta-se como uma proposta de educação em tempo integral, mas traz em seu âmago a fragmentação da formação dos jovens em cinco diferentes itinerários formativos, a redução da educação básica e diminuição das metas do PNE - Plano Nacional de Educação quanto ao atendimento das escolas de tempo integral.

Nessa "política" prevê-se "o repasse de recursos do Ministério da Educação para os Estados e para o Distrito Federal pelo prazo de dez anos por escola, contados da data de início da implementação do Ensino Médio Integral na respectiva escola". No material oficial de apresentação da política, divulgado junto com a MP da Reforma, propunha-se o atendimento de até 250 mil alunos de Ensino Médio em escolas de tempo integral, com investimento de 500 milhões por ano, em até 4 anos (depois alterado para 10 anos), sendo previsto o custo de $\mathrm{R} \$$ $2.000,00$ por aluno por ano. Estabelecia, também, um teto de atendimento de $5 \%$ das escolas da rede, sendo no máximo 30 por estado, o que significaria uma redução do atendimento definido pelo PNE, uma vez que a meta 6 deste Plano prevê $50 \%$ das escolas públicas e $25 \%$ dos alunos atendidos em escolas de tempo integral, até 2024.

Essas metas são extremamente tímidas, considerando o universo de alunos matriculados no Ensino Médio no Brasil (aproximadamente 8 milhões), mais ainda se considerarmos a 
população de 15 a 17 anos (aproximadamente 10 milhões) e observando, também, o valor total e o valor per capta previsto. A timidez não apenas demonstra a pouca disposição governamental para o financiamento da educação de tempo integral, mas revela que essa se constitui como uma miragem, que obscurece as reais finalidades e o conteúdo da Reforma em curso.

A educação integral, portanto, é apenas uma "farsa", uma desculpa para que se introduza aquilo que se coloca como fundamental, ou seja, a redução da educação básica, a desprofissionalização docente e a subordinação do Ensino Médio às demandas específicas do mercado 5 .

Uma das principais mudanças aprovadas é na redação do artigo 36 da LDB, que trata da organização curricular do Ensino Médio. Substitui-se a diretriz única de que devessem ser consideradas, na organização do ensino médio, "a educação tecnológica básica, a compreensão do significado da ciência, das letras e das artes; o processo histórico de transformação da sociedade e da cultura; a língua portuguesa como instrumento de comunicação, acesso ao conhecimento e exercício da cidadania" e em seu lugar são criados cinco diferentes Itinerários Formativos, com ênfase nas áreas de linguagens e suas tecnologias, matemática e suas tecnologias, ciências da natureza e suas tecnologias, ciências humanas e sociais aplicadas e formação técnica e profissional, organizadas de acordo com critérios estabelecidos em cada sistema de ensino e sendo o "itinerário formativo integrado" apenas uma possibilidade.

Esses itinerários serão oferecidos nos estados e no Distrito Federal conforme disponibilidade e decisão dos sistemas de ensino, e não por escolha dos estudantes, como diz uma propaganda televisiva do Governo Federal, induzindo os jovens a uma falsa ideia de autonomia.

Passa-se a admitir, também, a possibilidade de que parte do Ensino Médio seja integralizado por meio de reconhecimento de competências e/ou realizado a distância em outras instituições, "com notório reconhecimento".

Na prática, reduz o Ensino Médio ao tornar apenas 1.800 horas obrigatórias de trabalho com a BNCC, apesar de prever o aumento da carga horária anual para 1.000 horas, no prazo máximo de 5 anos, o que totalizaria 3.000 horas. Ou seja, $40 \%$ da carga horária do Ensino Médio prevista é flexibilizada, sendo a sua organização e oferta definidas pelos sistemas de ensino.

Torna, ainda, obrigatórias apenas as disciplinas de Português e Matemática nas três séries do Ensino Médio e o estudo da Língua Inglesa, em tempo não definido pela Lei. "Estudos e práticas de Educação Física, Arte, Sociologia e Filosofia" também são conteúdos obrigatórios, mas não são definidos como disciplinas, podendo, portanto, seus conteúdos serem "ensinados diluídos em outras disciplinas", como diz Ribeiro (2017) quando define o "novo Ensino Médio" como líquido.

\footnotetext{
${ }^{5}$ Associada a essa pretensa Política de Educação de Tempo Integral deve-se considerar a Portaria n. 1.145 , de $11 / 10 / 2016$, do Ministério da Educação, que institui a sua política de fomento à escola de tempo integral e que, na prática, induz as escolas a uma prática de "treinamento para o ENEM" como define o Prof. Luiz Carlos de Freitas (Unicamp-SP) no Blog do Freitas (https://avaliacaoeducacional.com/2016/10/11/portaria-1145-fomento-a-preparacao-paraprovas-em-tempo-integral/).
} 
Ao reduzir o Ensino Médio para 1.800 horas obrigatórias, na prática está reduzindo a educação básica. Minimiza-se ${ }^{6}$ o Ensino Médio e retira-se a relevância de matérias importantes para a formação da juventude, tais como Sociologia, Filosofia, História, Geografia, Física, Química, Biologia, Educação Física e Artes, ou seja, disciplinas que favorecem o desenvolvimento do pensamento crítico-racional e das amplas capacidades humanas necessárias ao comportamento autônomo e cidadão. Conceitualmente a reforma agride a ideia de educação básica também quando propõe a sua diferenciação em função da condição sócio-econômica dos alunos, dificultando aos jovens pobres, particularmente aos jovens trabalhadores, a possibilidade de uma trajetória escolar de base científica.

A Reforma também impacta profundamente a educação profissional técnica de nível médio, sendo a mesma colocada como uma das possibilidades de itinerários formativos. A formação técnica não deve ser necessariamente assegurada nas próprias escolas (o que demandaria um grande investimento em construção, aquisição de equipamentos, formação profissional e contratação de novos docentes, recursos para insumos, etc.), mas por meio do "reconhecimento de saberes e competências", admitindo-se "experiência de trabalho adquirida fora do ambiente escolar", em cursos oferecidos por "centros ou programas ocupacionais" nacionais ou estrangeiras ou realizados por meio de educação a distância, configurando um "vale-tudo" na educação profissional técnica de nível médio, destinada prioritariamente aos jovens de origem trabalhadora.

Nesse "vale-tudo" na educação profissional técnica passa-se a admitir, como docentes, "profissionais com notório saber reconhecido pelos respectivos sistemas de ensino, para ministrar conteúdos de áreas afins à sua formação ou experiência profissional”, abrindo-se uma exceção ao art. 62 da LDB, que definia que "a formação de docentes para atuar na educação básica far-se-á em nível superior, em curso de licenciatura, de graduação plena, em universidades e institutos superiores de educação".

A nova legislação também permite que cursos oferecidos por estes "centros" (que não têm qualquer regulamentação legal) sejam pagos com recursos do FUNDEB (por isso a necessidade de alterar a lei que regulamenta o financiamento da educação básica), o que deve favorecer a transferência de recursos públicos para empresas privadas de serviços educacionais diretamente pelo MEC ou por meio das secretarias estaduais de educação.

\section{ALGUNS SIGNIFICADOS E FINALIDADES NÃO EXPLÍCITAS DA REFORMA DO ENSINO MÉDIO}

\footnotetext{
${ }^{6}$ Minimalista é o sistema, doutrina ou tendência que defende a redução ao mínimo do que compõe algo (Ferreira, 2017).

${ }^{7}$ A legislação nacional não regulamenta a educação profissional inicial e continuada e nem define critérios ou exigências para o seu funcionamento. Do mesmo modo não define qualquer exigência ou condições para o funcionamento de "centros ou programas ocupacionais", podendo estas funções de formação profissional não técnica serem desenvolvidas por quaisquer agentes públicos ou privados que tenham interesses.
} 
Essa Reforma não é legítima, pois modifica de forma abrupta e antidemocrática a principal lei que regulamenta a educação nacional: a LDB. Ela altera também a Lei do FUNDEB e a CLT - Consolidação das Leis do Trabalho, em seu artigo 318, que trata da jornada de trabalho do professor, além de propor uma "Política de Educação Integral". Altera, também, a Lei n. 4.117, de 27 de agosto de 1962, que regula o Código Brasileiro de Telecomunicações, facilitando o estabelecimento de convênios entre o Ministério da Educação e empresas de radiodifusão.

Essa aparente confusão de finalidades cumpre a função de tornar efetiva a nova legislação, tornando-a mais orgânica e com fator de coerção bem definido.

Segundo Deluchey (2006), toda política pública pressupõe alguns elementos: a) um conteúdo, que revela a direção que seus elaboradores quer dar ao objeto da lei; b) um programa, composto de um conjunto de ações, regulamentos e definições de distribuição de recursos; c) uma orientação normativa, revelada pelas escolhas e construções ideológicas que produz um novo olhar sobre o setor de ação governamental ao qual se refere a política pública; d) fatores de coerção, que expressam a autoridade governamental sobre a sociedade; e e) a política é também um espaço de interação social, ou seja, ela se coloca em meio aos conflitos e interesses políticos coletivos e particulares, tornando-se um objeto de discussão e debates que produz consensos ou dissensos.

A legislação da Reforma em curso revela essas diferentes dimensões da Política e seu amplo alcance parece lhe dar maior organicidade e possibilidades de efetividade, mas, por outro lado, parece esconder a sua orientação normativa, ou seja, os valores que ela emerge e outros que ela submerge.

A Reforma é resultado de uma visão minimalista e instrumental do Ensino Médio, em conformidade com recomendações de diferentes organismos multilaterais, como a UNESCO Organização das Nações Unidas para a Educação, a Ciência e a Cultura e o pensamento privatista, com os quais compartilha valores. Em documento no qual faz recomendações para reformas curriculares do ensino secundário, em particular para "países com circunstâncias socioeconômicas altamente diferenciadas" e "países que revisam continuamente eficácia de seus sistemas de educação", a UNESCO, por exemplo, propõe que o Ensino Médio seja "dividido" em dois ciclos, em oposição à "educação secundária geral", tendo cada ciclo finalidades diferentes, tal como se observa abaixo:

Nesse nivel de ensino, particularmente durante seu primeiro ciclo, valores e atitudes formados na escola primária são enraizados mais firmemente, acompanhados da aquisição de conhecimentos e habilidades. O primeiro ciclo da educação secundária, por tanto, encontra-se conceitualmente dentro do conceito de "educação básica", que é amplamente reconhecido como requisito educacional mínimo para o desenvolvimento individual e social. Daí que em muitos lugares do mundo a educação básica seja compulsória e financiada pelo Estado (Unesco, 2008, p. 11).

Para o segundo ciclo pensado, toma-se como referência a experiência de alguns países europeus, assim explicitadas:

No segundo ciclo da educação secundária, os países europeus têm experimentado diversas abordagens de articulação entre educação básica geral e educação técnico-profissional e 
treinamento, que incluem diversificação do currículo, aumento do status e da qualificação docente, melhorias no encaminhamento profissional e intermediação com o ensino superior (Unesco, 2008, p. 18).

Note-se que, além de finalidades diferentes para os dois ciclos do Ensino Médio (em detrimento do que define a LDB como finalidade da educação básica), esse documento admite que apenas o primeiro ciclo assuma um caráter público e gratuito, pois "conceitualmente dentro do conceito de 'educação básica', (...) daí que (...) compulsória e financiada pelo Estado".

Esse documento da UNESCO, que serve como referência para a atual Reforma do Ensino Médio, reduz, portanto, o conceito de educação básica, como também o faz a reforma do ensino médio em curso, apesar de que esta não propõe claramente o fim da gratuidade do seu "segundo ciclo", na Reforma representado pelos itinerários formativos.

A visão minimalista revela-se ainda na proposição de um currículo mínimo, no qual obrigatoriamente seriam trabalhados apenas as disciplinas Português e Matemática nas três séries do Ensino Médio, tal como propõe a UNESCO, que defende currículos do Ensino Médio "baseados em competências genéricas essenciais", a saber:

Os conteúdos curriculares ou de aprendizagem abarcarão competências essenciais $e$ outras, opcionais, em função de necessidades específicas da coletividade. Competências essenciais tais como o letramento e a numerização serão reforçadas, desenvolvidas e complementadas com a responsabilidade cívica e a cidadania (Unesco, 2008, p. 17 - grifo nosso).

Tais "competências genéricas essenciais", segundo a UNESCO, seriam necessárias para o desenvolvimento das "personalidades produtivas", "responsáveis, bem equipadas para a vida e para o trabalho na atual sociedade do conhecimento baseada na tecnologia".

Daí se origina a chamada "flexibilização curricular" implementada pela Lei, tomada portanto como estratégia de submersão dos valores da "educação básica" e "educação pública, estatal e gratuita" e de emersão de valores de "educação mínima" e de "educação instrumental para o mercado", colocando o Ensino Médio a serviço da produção de sujeitos produtivos.

O objetivo da chamada "flexibilização curricular" não é democratizar a escola e considerar a diversidade de interesses dos jovens, mas propor itinerários que, tal como previa Althusser, reproduzam a força de trabalho diversamente, "conforme às exigências da divisão social-técnica do trabalho, nos seus diferentes "cargos" e "empregos" (...), uma instrução para os operários, uma para os técnicos, uma terceira para os engenheiros, uma última para os quadros superiores, etc. (Althusser, 1970, p. 57-58).

Esta flexibilização tende a manter a discriminação dos jovens em diferentes itinerários e com diferentes bases de conhecimentos escolares, aprofundando as desigualdades, além de, também, promover uma maior diferenciação (desigualdade) entre as escolas.

Os defensores da Reforma afirmam que a mesma tornará mais atrativo o Ensino Médio, por meio da flexibilidade, mas isso revela pelo menos dois equívocos: primeiro, a flexibilidade não é para os alunos, uma vez que cabe aos sistemas de ensino fazerem as opções dos itinerários a serem ofertados nas diferentes escolas. Consta da Lei que "a organização das áreas (...) será feita de acordo com critérios estabelecidos em cada sistema de ensino"; segundo, o currículo não 
é o único determinante da qualidade da educação ou atrativo da escola. Como a Reforma não faz nenhuma indicação acerca de outros fatores fundamentais intervenientes para a qualidade da educação e/ou para a motivação dos jovens (tais como infraestrutura da escola, matérias didáticos, valorização docente, etc.), essa supervalorização do currículo parece como mais uma tentativa de esconder as suas reais finalidades e valores. Como diz Frigotto (2010, p. 36):

Para a efetiva universalização democrática da educação básica (...) há necessidade de qualificar as condições objetivas de vida das famílias e das pessoas e aparelhar o sistema educacional com infraestrutura de laboratórios, professores qualificados, com salários dignos, trabalhando numa única escola etc.

A visão minimalista se revela, sobretudo, nas definições do chamado quinto itinerário, no qual se prevê a formação profissional, já que esta subentende uma formação profissional rasteira, capaz de preparar apenas para atividades laborais simples, pois, além de pressupor uma formação desvinculada da escolarização e de admitir professores sem licenciatura ou mesmo graduação ("profissionais com notório saber"), não prevê investimentos em educação profissional, mas a possibilidade de certificação e de financiamento público de serviços privados.

O caráter rudimentar do itinerário "formação profissional" revela-se ainda na possibilidade de que sejam certificadas "vivências práticas de trabalho no setor produtivo ou em ambientes de simulação", garantida a "certificação intermediária de qualificação para o trabalho" ou na oferta de cursos experimentais em "áreas que não constem do Catálogo Nacional dos Cursos Técnicos".

É um vale-tudo na educação profissional técnica, que poderá ser feita em módulos, a distância, por meio de convênios com instituições escolares ou não, ou mesmo sem o ensino, já que poderão ser certificadas competências adquiridas em experiências de trabalho ou em cursos oferecidos "por centros ou programas ocupacionais" ${ }^{8}$.

Em função das muitas críticas havidas, apesar de não prevista inicialmente, a nova legislação admite que, "a critério dos sistemas de ensino, poderá ser composto itinerário formativo integrado, que se traduz na composição de componentes curriculares da Base Nacional Comum Curricular BNCC e dos itinerários formativos".

A Reforma em curso também submerge outro conceito importante da educação nacional, fruto das lutas dos profissionais da educação: a profissionalização docente, bem como desqualifica as licenciaturas que formam para o exercício da docência na educação básica. Não apenas por que admite os "profissionais de notório saber" para a docência na formação profissional técnica, mas, e principalmente, porque ao colocar como obrigatórias apenas as disciplinas de Português e Matemática, torna todos os demais docentes das diferentes formações "dispensáveis". Isso tem o efeito imediato de maquiar o grave problema da educação nacional, que é a falta de professores qualificados para a educação básica nacional, uma vez que, com

\footnotetext{
${ }^{8}$ Não há qualquer normatização legal acerca do que seja "centro ou programas ocupacionais", podendo, portanto, ser qualquer coisa ofertada por qualquer organização.
} 
exceção de Português e Matemática, todas as demais disciplinas podem agora ser suprimidas dos currículos das escolas ${ }^{9}$.

Seja de modo explícito, considerando as referências citadas na justificativa da MP enviada ao Congresso Nacional, ou na consideração dos valores que a Reforma carrega, identificam-se alguns dos seus principais interlocutores no País, o CONSED e o Movimento Todos pela Educação, tendo como referência teórica a TCH - Teoria do Capital Humano ${ }^{10}$. A Reforma atende ao CONSED principalmente quando desobriga as secretarias de educação de formação e contratação de professores licenciados, em virtude de que a falta de professores pode ser contornada pela não obrigatoriedade de oferta de onze das treze disciplinas antes consideradas obrigatórias no currículo do Ensino Médio ${ }^{11}$. A Reforma também atende ao "Todos Pela Educação" quando impõe ao Ensino Médio Brasileiro a lógica de mercado, seja nas suas finalidades, de formação de personalidades produtivas, ou ampliando as facilidades de as empresas de serviços educacionais acessarem os recursos públicos.

Como resultado e em substituição a ideia de de formação básica comum, impinge-se aos jovens de origem trabalhadora uma formação rasteira, instrumental aos ofícios a eles "predestinados" e para os quais são necessários apenas os chamados "saberes de base". A Reforma, portanto, mantém o caráter das reformas da educação do final do Século XX nos países ocidentais, analisadas por Azevedo (2013) da seguinte forma:

Na esfera pública de ensino, principalmente a partir das reformas para a educação do final do final do século $X X$, tem predominado (retornado?) a estratégia dominante da semicultura (ADORNO, 1996) para a educação de massas e a cultura elaborada para as elites ou, como sugere Derouet, "uma formação de excelência no seio de redes internacionais destinadas à elite; e, para a mão-de-obra, o retorno aos saberes de base [Back to Basis]" (2009, p. 35). (Azevedo, 2013, p. 143).

A ideia de "saberes de base" pressupõe uma semiformação, ou uma formação que assegure aos jovens pobres o acesso apenas a fragmentos da cultura letrada, como defendia Gustavo Capanema, na década de 1930, no Brasil. Para esse Ex-Ministro da Educação Nacional, a coexistência de dois tipos de escola de Ensino Médio seria uma necessidade: uma escola formadora das elites condutoras da nação, com a finalidade de formar "homens que deveriam assumir as responsabilidades maiores dentro da sociedade e da nação"; e uma escola voltada para as massas, a qual combinaria a "preparação técnica do trabalhador" e a inculcação "nas massas dos verdadeiros valores nacionais (o espírito brasileiro), de forma que estas acatassem a legítima autoridade dos líderes nacionais" (Mendonça, 2009, p. 121).

${ }^{9}$ Deve ser importante o efeito negativo da reforma em programas emergenciais de formação de professores tal como o PARFOR - Plano Nacional de Formação de Professores.

${ }^{10}$ Sobre a TCH, sugerimos a leitura de FRIGOTTO, Gaudêncio. Educação e a Crise do Capitalismo Real. São Paulo, Cortez, 1995.

${ }^{11}$ Esse grave problema da educação nacional, é importante pontuar, revela-se nos dados do INEP Instituto Nacional de Estudos e Pesquisas Educacionais Anísio Teixeira, que revelam a necessidade de contratação, no ano de 2013, de 231.886 professores para suprir a carência identificada no Ensino Médio Regular, sendo maior essa carência para as disciplinas de Física, Sociologia, Química, Artes e Filosofia, todas tornadas "descartáveis" pela Reforma em curso. 
A Reforma tende a ter outro efeito, o de aprofundar as desigualdades e de reduzir o papel das escolas como fator de geração de oportunidades educacionais, citado por Colemann (2011). Este autor considera que o tema das oportunidades educacionais ganha relevância na sociedade moderna quando surge a proposta de "currículo diferenciado do ensino secundário", considera também que um programa acadêmico numa escola secundária tem o efeito de manter em aberto as oportunidades educacionais, mas também de encerrar oportunidades. Para o autor

A ideia de uma experiência educacional comum implica que esta experiência tenha apenas como efeito o alargamento do número de oportunidades e nunca o efeito da exclusão de oportunidades. Porém, claramente, isto nunca será inteiramente verdade enquanto esta experiência impedir uma criança de seguir determinados percursos educacionais (Colemann, 2011, p. 141-142).

Considerando então que uma experiência educacional gera "estreitamento de oportunidades" quando impede uma criança de seguir determinado percurso, pode-se considerar este possível efeito da Reforma em curso, que tenta associar o currículo das escolas do Ensino Médio com o "futuro previsto para os jovens", encerrando, portanto, a trajetória de vida desses àquilo que venha a ser determinado pelos sistemas de ensino como itinerários formativos a eles destinados.

Esse autor critica a ideia de que haveria "desigualdade" se fosse assegurado, a todos, um currículo que serve somente à minoria que entrará na universidade e que, portanto, seria mais "igualitário" oferecer currículos diferenciados.

Tal como na Reforma em tela, diz Colemann:

A ideia inerente ao novo currículo (diferenciado) do ensino preparatório e secundário parecia ter sido a de assumir, como dado adquirido, os diversos percursos profissionais que os adolescentes iriam seguir depois da escola preparatória e secundária e a de refletir (implicitamente) que existe uma maior igualdade de oportunidades educacionais para um rapaz que não vá para a universidade se ele tiver um currículo apropriado do que se tiver um currículo delineado para a entrada na universidade (Colemann, 2011, p. 143).

Mesmo admitindo que este seja um dilema originado pela própria estrutura social, tendo em vista que a desigualdade escolar é diretamente relacionada com a desigualdade social, "a característica que distingue este conceito de igualdade de oportunidades educacionais é o facto de que este aceita como dado o futuro associado a criança" (Colemann, 2011, p. 143).

A lógica que preside esta ideia pressupõe, portanto, uma amarração entre currículo escolar e futuro dos jovens, como se isso fosse possível. Na prática, tende a calcificar as desigualdades educacionais diretamente ligadas às desigualdades sociais, promovendo um verdadeiro cerco ao futuro dos jovens pobres, que terão muito mais dificuldades de reconstruir o seu "destino" ou mesmo de ingressar numa universidade, se este tiver cursado um itinerário formativo diferente daquele por ele cursado ou se tiverem cursado o itinerário de formação profissional.

\section{CONSIDERAÇÕES FINAIS}


A Reforma em curso, em nome da "educação integral", promove a fragmentação e o fatiamento do Ensino Médio. Em nome da flexibilização curricular, tida como democrática, favorece processos de exclusão, uma vez que a maior diversificação/diferenciação escolar numa sociedade de profundas desigualdades como a brasileira pode agudizar os processos de exclusão dos jovens mais vulneráveis: pobres, negros, moradores de periferias, ribeirinhos etc., em virtude de que as suas experiências escolares tendem a ser mais instrumentais.

Como a reforma foi pensada principalmente para as escolas estaduais, a flexibilização pode, contraditoriamente, ter efeito positivo apenas nas escolas com infraestrutura diferenciada e corpo profissional qualificado e com carreira definida, permitindo o enfrentamento da fragmentação curricular, tais como as particulares e as escolas federais. Para estas, em que os profissionais não têm que disputar carga horária e em que há espaços, tempos e acúmulos para a formulação pedagógica, abre-se uma real possibilidade de inovação curricular com o desenvolvimento de novos desenhos curriculares e diferentes estratégias de ensino e de aprendizagem, para o que o ensino integrado continua sendo um desafio possível. - Como a reforma foi pensada principalmente para as escolas estaduais, as escolas com infraestrutura diferenciada e corpo profissional qualificado e com carreira definida podem ter melhores condições de enfretamento à fragmentação curricular, tais como as escolas federais.

A Reforma tende a enfraquecer alguns efeitos positivos que a escola básica produz em países subdesenvolvidos como o Brasil, como a redução das desigualdades e a produção de mobilidade social (Heyneman, 1983). Ao propor uma amarra entre currículo e trajetória juvenil, a reforma limita o potencial da escola em produzir oportunidades educacionais, principalmente as vinculadas as redes estaduais de ensino que respondem por cerca de $80 \%$ das matrículas do Ensino Médio Brasileiro, cerceando as expectativas de futuro dos jovens.

Em direção oposta ao que a Reforma indica, coloca-se a necessidade de defesa da formação comum a todos os jovens, pois foi uma conquista que a LDB de 1996 definisse o Ensino Médio como uma etapa da educação básica. E esta formação comum pressupõe uma educação inteira e um currículo do Ensino Médio rico, variado, garantindo o acesso a ciência, a cultura e aos desportos, capazes de fornecer bases sólidas para a formação do cidadão pleno, capaz de trabalhar e de viver dignamente na sociedade contemporânea.

Para isso é necessário defender a obrigatoriedade das disciplinas que tem a função de socializar saberes de reconhecido valor social (saberes universais) tais como Filosofia, Sociologia, Física e Biologia, que têm a função de assegurar o conhecimento sobre o funcionamento dos fenômenos físico-sociais bem como a formação do pensamento racional-crítico.

Em relação ao ensino técnico é necessária a defesa, ainda, do Ensino Médio Integrado, que tome em unidade a formação técnica específica e a formação científica, bem como um combate a toda forma de aligeiramento tornada possível pela nova legislação.

Em relação a educação de tempo integral, diferente do que prevê a Reforma, é necessária a defesa de fontes perenes de investimento para as escolas públicas, em particular para aquelas atendem aos alunos em tempo integral, que requerem, entre outras, a ampliação e a melhoria de sua infraestrutura. Requer, ainda, um posicionamento crítico em relação à admissibilidade de uso 
de recursos do FUNDEB para o financiamento de empresas de serviços educacionais ou para uso das OSs - Organizações Sociais.

A reforma também coloca os professores em situação de maior vulnerabilidade, por isso se coloca a necessidade de um firme posicionamento em defesa da profissionalização docente e contra a admissibilidade do professor de notório saber na educação básica.

A Reforma em curso, como vimos, responde principalmente a interesses de seus principais interlocutores, o CONSED, ao flexibilizar a necessidade de contratação de professores licenciados, e o Movimento Todos pela Educação, ao direcionar o currículo para a formação das "personalidades produtivas" e estimular o "mercado de serviços educacionais". Atende, portanto, a esses interesses em detrimento do futuro dos jovens e com a possibilidade de aumento das desigualdades entre estes.

Romper com essa lógica de mercado que se impõe à educação básica pública é uma condição para o enfrentamento às desigualdades, ou como diz Azevedo (2013):

Políticas públicas de promoção da igualdade substantiva e de universalização de acesso a bens públicos (desmercadorização) são verdadeiros seguros antifalência das famílias, de indivíduos e de cidadãos e de construção de sociedades solidárias.

Como afirmamos anteriormente, toda política é também um espaço de interação social, sendo objeto de aceitações, rejeições ou reinterpretações. Ela deve ainda ser considerada principalmente segundo as estruturas criadas e não conforme as finalidades explicitadas. Por isso e por entender que as políticas sofrem determinações por condições que não são levadas em consideração nos seus planejamentos, consideramos ser crucial para a forma como ela vai ser entendida e implementada a mobilização de estudantes e profissionais da educação, estes os principais sujeitos da educação. Estes, sim, podem alterar, barrar ou modificar, com a sua prática cotidiana, alguns efeitos negativos "previsíveis" da Reforma em curso, por exemplo, promovendo ações de desmercadorização do Ensino Médio e encontrando formas coletivas, democráticas e inovadoras de enfrentamento à fragmentação curricular.

\section{REFERÊNCIAS}

Althusser, Louis. (1970). Ideologia e Aparelhos ideológicos de estado. Lisboa: Presença.

Azevedo, Mário Luiz Neves de. (2013). Igualdade e equidade: qual é a medida da justiça social? Avaliação (Campinas) [online]. 2013, vol.18, n.1 [cited 2016-08-22], pp.129-150. Available from: $<$ http://www.scielo.br/scielo.php?script=sci_arttext\&pid=S1414-

40772013000100008\&lng=en\&nrm=iso>.

Brasil. (2017). Medida Provisória MPV 746/2016. Brasília, 22 set. 2016a. Disponível em: <http:// www.planalto.gov.br/ccivil_03/_ato2015-2018/2016/Mpv/mpv746.htm>.

Coleman, James. (2011). O Conceito de igualdade de oportunidades educacionais. In: Revista Educação, sociedade e culturas. 34. 2011. 137-155.

Deluchey, Jean-François. (2006). Teoria das políticas públicas - análise cognitiva. Texto. 2006. 
Ferreira, Aurélio Buarque de Holanda. Dicionário do Aurélio. Disponível em https://dicionariodoaurelio.com/. Acessado em 04/05/2017.

Ferreti, Celso João, \& Silva, Monica Ribeiro da. (2017). Reforma do Ensino Médio no Contexto da Medida Provisória no 746/2016: Estado, currículo e disputas por hegemonia. Educação \& Sociedade, 38(139), 385-404. https://dx.doi.org/10.1590/es0101-73302017176607

Freitas, Luiz Carlos. Portaria 1145: Fomento à Preparação para Provas em Tempo Integral. In: https://avaliacaoeducacional.com/2016/10/11/portaria-1145-fomento-a-preparacao-paraprovas-em-tempo-integral/. Acessado em 01/05/2017.

Frigotto, Gaudêncio. A educação é um dos serviços mais lucrativos, afirma Gaudêncio Frigotto. In: http://www.mst.org.br/2015/09/15/a-educacao-tem-se-tornado-um-dos-servicos-mercantismais-lucrativos-afirma-professor-da-uerj.html. Acessado em 01/05/2017.

Frigotto, Gaudêncio. (2010). A relação da educação profissional e tecnológica com a educação básica. In: MOLL, Jaqueline et al. Educação profissional e Tecnológica no Brasil Contemporâneo. Proto Alegre, Artmed: 2010.

Heyneman, Stephen P.; Loxley, William A. (1993). The Effect of Primary-School Quality on Academic Achievement: Across Twenty-nine High-and Low-Income Countries. American Journal of Sociology. Vol. 88, No. 6 (May 1983), 1162-1194.

INEP - Instituto Nacional de Estudos e Pesquisas Educacionais Anísio Teixeira. Censo Escolar 2013 - Perfil da Docência no Ensino Médio Regular. Disponível em http://www.publicacoes.inep.gov.br/portal/download/1281. Acessado em 04/05/2017.

Mendonça, Ana Waleska Pollo Campos. (2009). Aprendendo com a História. In: Pará - SEDUC. Ensino Médio Integrado no Pará como Política Pública. Belém: Seduc.

MINISTÉRIO PÚBLICO FEDERAL. PFDC lança nota pública sobre riscos de reforma do ensino por meio de medida provisória. In: http://pfdc.pgr.mpf.mp.br/informativos/edicoes2016/setembro/pfdc-lanca-nota-publica-sobre-riscos-de-reforma-do-ensino-medio-por-meio-demedida-provisoria/. Acessado em 01/05/2017.

Ribeiro, Mônica. (2017). Como fica o ensino médio com a reforma - vem aí o Ensino Médio "líquido". Texto. 2017.

Saviani, Dermeval. A Crise Política Atual: Uma Grande Farsa. In: https://avaliacaoeducacional.com/2016/04/02/saviani-e-golpe-sim/. Publicado em 02/04/2016. Acessado em 01/05/2017.

UNESCO - Organização das Nações Unidas para a Educação, a Ciência e a Cultura. (2008). Reforma da Educação Secundária. Brasília: UNESCO. 